\title{
The Challenges of Implementing Diverse Political Directives in Contemporary China: Between Creativity and Confucianism
}

\author{
Wai-Chung Ho
}

\begin{abstract}
The People's Republic of China (PRC) was founded as a communist state in 1949 within the framework of the collective leadership model under the Communist Party of China (the single-party system in China). After experiencing sociopolitical and economic changes, the PRC has moved to the free market economy of globalisation in the global age. The evolution of Chinese politics and the economic system has resulted in more diversity and changes in school education, along with struggles to adjust to these changes. Along this line, this chapter will examine the complex relationship between the politics of diversity, Confucianism, and creativity education, particularly in response to the views of Chinese teachers from Beijing via in-depth, semi-structured individual interviews on the implementation of a creativity policy in school music education. Based on current education policies and the interview data collected for this study on the examination of the nature of creativity, this chapter will conclude with a discussion of how school music education may help initiate a dialogue on the politics and nature of creativity and cultural identity in response to the challenges of contemporary political and cultural values between creativity and Confucianism that prevail in the global age of China.
\end{abstract}

Keywords Contemporary China $\cdot$ Politics of diversity $\cdot$ Creativity in music education · Between creativity and Confucianism · Teacher's perceptions

\footnotetext{
W.-C. Ho $(\bowtie)$ e-mail: tediwch@hkbu.edu.hk

Department of Music, Hong Kong Baptist University, Kowloon Tong, Hong Kong, China 


\section{China's Dream}

Over the last two decades, creativity development in China has been bolstered by strong government support, economic transformation, and technological advancements. Simultaneously, China has experienced a steady decline in central government control over the political system, society, and the economy as a whole, resulting in increased cultural and industrial diversity. President Xi Jinping noted that China needs to go through three transitions in order to take the global stage and to advance an open world economy: "From China's speed to China's quality; from China's products to China's brands; and from 'made in China' to 'created by China" (Liu 2016, p. 53). "Made in China 2025" (a 10-year industrial plan announced in October 2015) is a strategic plan for the future of China's industrial modernisation, with an emphasis on increasing its business with the rest of the world. The supportive role of Chinese authorities has encouraged greater participation among private and educational sectors in this national development process. However, Chinese education also intends to integrate contemporary Chinese politics and Confucianism into the curriculum, as can be seen in the implementation of creativity directives in education.

Chinese education has long been criticised for its focus on the mastery of knowledge and on test-taking at the expense of students' critical thinking and creativity; it has also been condemned as unhealthy, as it emphasises discipline, drilling, and rote memorisation (Watkins and Biggs 2001; Zhao 2012). The philosophy of Confucian education and its policies have become central to the curriculum, particularly through the establishment of the Confucius Institutes programme affiliated with the PRC's Ministry of Education (MoE) in 2004. This policy is the latest and greatest of the Chinese authorities' efforts to embrace Confucianism and traditional culture, which are regarded as the constitutional role of education (see Billioud and Thoraval 2009; Yau 2018). Traditional Chinese classics are regarded as basic moral education materials for children and their achievement of the contemporary "China's Dream" (Ambrogio 2017, p. 124). After Xi Jinping became the leader of China upon his selection by the CPC at the CPC's 18th Party Congress in 2012, his use of the words "China's dream" (as a description of China's national rejuvenation to construct a better society) has appeared across state media platforms, in schools, and throughout other social media platforms to promote the Confucian virtue of filial piety.

In this chapter, I will examine the extent to which Chinese music teachers view traditional music teaching and creativity education (which is referred to as cultivating students' imagination and critical thinking) as the aim of school music education (see MoE 2011, p. 4, 2017 p. 2), as well as the challenges of teaching creativity in school music education in response to these diverse political directives. With particular reference to school music education in Beijing (the capital of China), this study examined the under-researched relationships between political transformation, cultural diversity, creativity, practices, and challenges in teaching, focusing on culture-based creativity. Beijing has a well-established education system, from preschool to teacher education. The curriculum of elementary and secondary schools 
in Beijing is a model of the national curriculum. To analyse the impact of relevant social changes and politics on creativity in music education, this chapter will employ the analysis of official documents, an interview survey of school music teachers, and other relevant literature. This chapter will cover three areas: (1) the policy demands of music education in a changing sociocultural climate; (2) teachers' perspectives on teaching creativity in school music education; and (3) a discussion of the challenges of teachers who find themselves caught between the ideal of creativity and those of obedience and order and the contradictory relationships in the curriculum between creativity education and traditional Chinese education and Confucianism. I argue that creativity in school music education has been limited by the official teaching materials regulated by Chinese politics and the extent of teacher education, as well as the provision of training courses for both pre-service and in-service teachers.

\section{The Policy Demands of Music Education in a Changing Sociocultural Climate}

With a view to removing impediments to Chinese economic reforms, President $\mathrm{Xi}$ has promoted a new moral education campaign in the form of "Socialism with Chinese Characteristics for a New Era" to stress the teachings of Confucius, particularly obedience and order. In a speech presented by President Xi on 24 September 2014 , at an international symposium to commemorate the 2565 th anniversary of the birth of Confucius in Beijing, President Xi supported the rejuvenation of Chinese culture with Confucian values by authenticating the official endorsement of Confucianism. For example, the MoE has maintained that the experience of arts education and music education in school learning should result in a moral education by aesthetic means (Ho 2010; Xu 2016; Zhao 2009). For the sake of Chinese political ideologies, Chinese teachers are now encouraged to be more culturally sensitive to the process of school education (Liu and Feng 2015).

At the same time, with a view to enabling China to compete in a globalising age, China, from the 1980s to the 2010s, has enacted various stages of education reforms to promote best practices in education, with particular emphasis on creativity, critical thinking, innovation, moral education, and character education for personal integration and social advancement in a global context (see MoE 2001, 2011, 2017). The Chinese Government's cries for expanding "creativity" have arisen as a response to "new calls" for schools to rebuild educational practices and ideology (Woronov 2008, p. 401). Teachers in China have conceptualised the factors of creativity, including "critical thinking, independence, and motivation", though obstructing factors involve the "evaluation system and resource limitations", while creativity has been easily displayed in the arts and sciences (Zhou et al. 2013, p. 239).

Three official documents-the 2005 "Nine-Year Compulsory Middle School Education Instructional Outlines" (i.e. a guide to teaching practices for 9-year 
compulsory middle school education), the 2005 "Nine-Year Compulsory Elementary School Music Education Instructional Outlines" (i.e. a guide to teaching practices for elementary school music education), and the 2011 "National Music Curriculum Standardization for Compulsory Education" (i.e. a music curriculum guide for compulsory school music education) - have provided a new conception of school music education (Zhang 2017, p. 71), including a focus on aesthetic education as the core of school music education, exploration of the richness and diversity of music cultures, respect for and love of diverse cultures, advocacy of musical creativity, individual development, and the promotion of an integrated approach across disciplines (Ho 2010, 2017). In addition, in 2010, the MoE issued the Notice about Creating Art Schools to Inherit Fine Chinese Culture in Primary and Secondary Schools in China in an attempt to improve the quality of students' knowledge of the arts and to help them to be active participants "in diversified and colourful artistic activities" (Guo 2013, p. 18). According to this guide, the aim of school music education is to provide aesthetic experiences, model perfect morals, enlighten wisdom, enhance creativity, highlight national arts, increase the understanding of world music, strengthen friendship and communication among people, and build a harmonious society (MoE 2011, p. 1, 2017, p. 1; also see Xiong and Zheng 2012).

\section{The Study of Teachers' Views on Creativity in Music Education: School Music Lessons in Beijing}

In Beijing's schools, music is a compulsory subject in the school curriculum for 9 -year basic education. Most schools present two weekly 40-min music lessons in Grades 1 through 5 and one music lesson per week in Grade 6, while secondary schools usually offer one weekly 40- to 45-min music lesson in the curriculum. The class size of both primary and secondary sectors usually ranges between 35 and 50 in each class. The most popular adopted music textbooks are published by the People's Music Publishing House (the only national publishing house in China) and the People's Education Press under the leadership of China's MoE. Based on Ho's analysis (2019) of these two selected textbooks, the feature of creativity materials is mainly on composition/improvisation activities. These textbook materials are also an attempt to explore the connection between creativity and the elements of Confucianism regarding family values and obedience to teachers (Ho 2019). Under the new instructions implemented by the $\mathrm{CPC}$, the MoE has taken steps to revise all liberal arts textbooks with a view to enhancing students" "socialist core values" in primary and secondary schools (Gao 2017).

In response to the sociopolitical context, education in Beijing takes place within a diverse landscape. The recent education reforms in China have been a challenge to developing students' creativity as the key movement to improve the nation's education in Beijing (Woronov 2008). Besides the implementation of creativity education, President $\mathrm{Xi}$ has emphasised that "socialist education with Chinese 
characteristics has been focused on nurturing the younger generation" (Xinhua Net 3 September 2018). The Commission of Education has stated that all kindergarten and primary school teachers in Beijing are now required to receive $40 \mathrm{~h}$ of training on the core values of Chinese socialism and traditional Chinese culture by 2020 (see Cui 2017).

Creativity and diversity in Chinese school music education has largely been implemented in terms of the teachers' selection of music genres and activities. However, the teachers' own perceptions of what creativity in music education is, and should be, have not been investigated. In light of recent education reforms (MoE 2011, 2017), the study reported in this chapter explored the extent of the diversity of ways musical and nonmusical elements can be taught and learned in China's music curricula in response to political diversity in China. The research intended to examine the status of music in education and teacher education in Beijing to provide a fuller understanding of the process of creativity education in school music learning. Focusing particularly on teachers working in Beijing, the main purpose of the study was to collect music teachers' views on the challenges they experience in teaching creativity in school music education and their instructions and practices of creative music learning in response to the implementation of the creativity policy in the school curriculum.

\subsection{Research Method}

As elsewhere in China, it is difficult for outsiders to gain access to schools for research purposes; consequently, these schools and school teachers were accessed mainly through local academics. Thus, the sample of teachers could not be selected randomly, nor were they purposefully chosen. The study employed semi-structured interviews as the major data collection method. All of the individual interviews were conducted between the summer and autumn of 2017. The sample involved one-onone interviews in Putonghua (a standardised variety of Chinese and the sole official language of the PRC) via Skype, and the in-depth, semi-structured individual interviews with 15 elementary and 13 secondary school music teachers from government schools in Beijing, mainly located in urban areas, elicited their views on students' creativity learning in school music education.

The teacher informants desired anonymity in the study, and they maintained that they would not sign the informed consent form; however, they had an opportunity to read the consent form beforehand. They were also advised that the interviews would be recorded; they were informed of their right to withdraw from the interview process if they were uncomfortable; they were told that the recording of the interviews could be stopped at any time upon request; and they were given the opportunity to choose the day and time of their interview. All interviews were audio recorded with the permission of the interviewees and generally lasted from $40 \mathrm{~min}$ to an hour; the recordings were destroyed immediately after the interviews were transcribed. In addition to being asked to provide certain personal background 
information, the individual semi-structured interviews were mainly guided by a series of open-ended questions (including the teachers' views on the aims of school music teaching and major changes in school music education, their opinions on the use of music textbooks and creativity in education, and their perspectives on teaching creativity via diverse music cultures). This qualitative study collected audio and visual data from the respondents using voice and video across the Internet via a synchronous (real-time) connection, and the interviews were transcribed afterwards. The thematic analysis focused on the organisation and rich description of the data set before moving on to identifying implicit and explicit ideas within the data (see Braun and Clarke 2006; Yin 2014).

\subsection{Major Findings of the Study}

A small sample of 28 music teachers from 28 schools was involved in the study. The interview findings from the 28 music teachers revealed the practices and challenges of fostering creativity in music education in general. Among these 28 teacher interviewees, only 2 were male teachers. ${ }^{2}$ Teaching experience ranged between 1 and 10 years (most teachers had 3 years or more of teaching experience).

\subsubsection{Teachers' Perceptions of the Aims and Changes in School Music Education}

Overall, all the teacher interviewees agreed that music should be part of the compulsory school curriculum. Most of them generally believed that music education as aesthetic education was the prevailing philosophy of school music education and school music instruction was expected to have a demonstrable impact on students' musical lives in ensuing years. According to the teacher interviewees, efforts to achieve the aim of aesthetic education through music education were many and varied; for example, teachers described their wishes as follows:

To cultivate students' love and enjoyment of music.

To explore music and its other forms and their cultural connections.

To understand music and its integration with other subject disciplines.

To improve students' aesthetic qualities and enrich their emotional experiences.

\footnotetext{
${ }^{1}$ The reporting of a few questions in the interview guide was omitted in this chapter, as they were not along the theme of analysis and discussion.

${ }^{2}$ Teacher training programmes graduate far more females than males. In particular, teaching in elementary schools has long been dominated by female teachers in China. The call for more maleoriented education has prompted a broader debate about gender imbalance, gender inequality, and social identity in school education.
} 
To cultivate artistic sentiment and excellent character qualities that affect students' lives.

Surprisingly, only 1 teacher (out of 28) stressed that "[h]elping students to have selfawareness, to know and to identify themselves, to be innovative, and to accept new ideas" should be important aims in classroom music instruction.

All the teachers felt that they were either not forced by their schools or had a consensus among teachers to teach creativity in school music instruction. However, some of them reflected that the discussion on this topic became clouded as the term "aesthetic education" was used in different ways and in different contexts associated with music and the arts in the dimension of experience in any discipline. One teacher pushed her school to integrate more education changes into its creativity policy for school education because, as she stated in the interview:

[m]y students have to prepare for studying abroad. Most of them will study in the United States and the United Kingdom. We assume that these overseas schools are more likely to admit creative students, as students are required to show their creativity in their applications. Hence, our school curriculum has attempted to integrate creativity education for their educational preparation.

\subsubsection{The Use of Textbooks in Creativity Teaching}

Only one teacher noted that the recent publications of music textbooks largely included creativity elements and moved away from traditional instruction prioritising the transmission of musical knowledge. Most teacher interviewees generally conceived that the biggest change in music education was the popularity of music textbooks' adoption of Western musical notation (a set of five horizontal lines and four spaces that represents a different musical pitch). ${ }^{3}$ The other major changes included the comprehensive training of students' musical capabilities in music-making with respect to performing, composing/improvising, and listening (or music appreciation); an emphasis on the promotion of traditional Chinese music; the development of quality teaching; and a strong emphasis on the professional quality of teachers for both pre-service and in-service music education. One teacher said that the official music textbooks were very traditional and boring and she could not figure out how to cultivate creativity with these old-fashioned teaching materials. One young teacher noted that she entered her teaching career a short time ago and she mainly followed the textbooks to conduct music instruction in the classroom; thus, she had no idea how to carry out creativity in her music lessons.

\footnotetext{
${ }^{3}$ The simplified musical notation (also known as jianpu or numbered musical notation) has been widely adopted in music publications (including music textbooks) in China. It is an adaptation of the French Galin-Paris-Cheve system that gained importance in the eighteenth century. It uses a

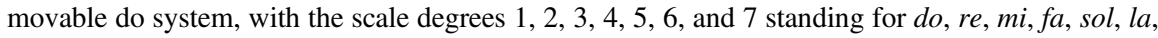
and si. This notation designates musical notes through a system of numbers (for pitch), dots (for octaves), and lines (for note length).
} 


\subsubsection{Recognising Creativity and Learning Diverse Music Styles}

When asked about the extent of how well their schools helped students learn about creativity through various music styles, such as traditional Chinese music, Western classical music, and other world music, most teachers believed that they should support teaching and learning about and through other music cultures. They were also aware that they should introduce a wide variety of styles and genres of music and songs in their classroom music instruction. Some teachers illustrated examples of Western classical music, jazz and bossa nova, traditional Chinese music, Chinese folk songs, and African music and how these music genres could bring a unique style in exploring the possible relationships between the understanding of world music and creativity in classroom music learning. For example, one teacher claimed that she helped her students develop an attitude of creativity by discovering folk songs from Northwest China, as she knew about musical creativity and social interactions in Northwest China.

Through music listening activities (or music appreciation), the teachers conceived that the students could cultivate their ideas and make imaginative use of musical elements and musical devices. Many teachers agreed with the listening approach, and they encouraged their students to participate in group activities, which implied a comprehensive approach to creative music-making (particularly with a combination of musical elements such as melodies and rhythms). A few other teachers believed that the arts-integrated curriculum expressed their views about integrated curriculum implementation with other arts and language subjects. For instance, one primary school teacher described how she utilised the selection "The Aquarium" from Carnival of the Animals by Saint-Saens to provide an interactive listening activity that motivated students to divide themselves into different groups and improvise movement activities to interact with the music.

\subsubsection{Fostering Musical Creativity and Its Limits in School Education}

Though the teachers did not highlight musical creativity as the aim of school music education, many of them generally agreed that teachers should attempt to find ways to implement creativity in their overall school education, as well as in their classroom music instruction. For example:

I believe that creativity education should be included in school music education. For instance, students should create melodies, improvise songs, dances, and musical sitcoms, and so on.

Of course, children's thinking is divergent.... We should respect their divergent thinking and encourage them to learn and to express themselves creatively.... At this point, I consider myself open-minded and hard-working (though not good enough) in promoting their creativity. 
I don't know much about creativity and creativity in school music education. But I believe that creative education is essential. . . and I also believe that I should select appropriate means to inspire and guide my students in their creations.

Creative education should be carried out. This is the requirement of the times and is also in line with student development, as well as the official stipulation....

Traditional music education (such as singing) is no longer satisfying and cannot attract our students' attention in classroom music learning....

Overall, the teachers agreed that integrating creativity education into school music education could help learners to develop creative capabilities (i.e. the skills and attitudes needed for creative, imaginative, and innovative thinking).

Though the teachers maintained that students should have a creative, stimulating classroom environment in which to embrace creativity as part of learning, they also felt that their own teaching of creativity was narrow and limited. One teacher said that she did not promote creativity in her music classroom, as she taught senior secondary school music and did not find that the creative components were important for senior form students. Another teacher revealed that the class size in Beijing was generally very large, with a range of 35-49 students in each class, so there was no way to conduct creative activities in the classroom. Other limitations to conducting creativity in school music education included restrictions on syllabus boundaries by policy implementations and little support in the present music textbook materials for teaching creativity in the classroom. A few teachers expressed that they had no idea how to teach creativity in their classroom music lessons, as shown in the following:

I think we have many difficulties in implementing creativity in school music education and the problems are beyond my expression.

We are used to having singing performances in classroom music lessons. It would be very difficult to adapt to the new teaching methods to cultivate my students' creative musicmaking.

I have attempted to introduce creativity into my classroom music lessons, but I cannot tell whether my students find these activities to be the most interesting activities.

I am teaching senior secondary school students, and my creativity teaching for them is little. I believe that creativity may not be suitable for these senior grade students.

Some teachers expressed that the difficulties in fostering music activities for students were due to the students' musical backgrounds and their diverse learning abilities and learning motivation, and thus they conveyed that teaching music composition might be difficult to achieve in their classes. 


\section{Discussion}

Up until the end of the twentieth century, Chinese teachers were criticised for limiting creativity and creative ideas in their classroom teaching. However, creativity in music education in contemporary China has been promoted in the past two decades, resulting in new opportunities as well as challenges. China's current political culture is mainly dominated by Confucianism and President Xi Thought on socialism with Chinese characteristics for a new era, in which individuality is discouraged. Moreover, schools are now required to integrate patriotism into their examinations and courses for the arts, Chinese language, ethics, geography, history, and physical education (Lau 2016). In this section of the chapter, I will discuss how school music education may help initiate a dialogue on Chinese-adopted creativity education amidst diverse political directives in the global age of China. In response to the main research question on the challenges of contemporary Chinese politics, the discussion will consist of two seemingly contradictory relationships in the curriculum: between creativity education on the one hand and traditional Chinese education and Confucianism on the other and between official approved teaching materials and teachers' perceptions of teaching creativity. This line of questioning views creativity in music education as a cause of political and cultural endeavours, not just as an effect of individual creation and educational development in Chinese school music education.

First, the role of school education involves both teaching creativity and Confucianism, for example, having Chinese students take part in competitive contests on Confucian culture. Confucian education seeks to foster desired character attributes, such as collectivism, respect, trustworthiness, social harmony, and love for people and the nation. Looking at China's music education, its breadth of view includes educational aims and values, as well as creativity, which have been transformed by the underlying beliefs of the sociopolitical system. With a view to achieving a global economy in the twenty-first century, Chinese authorities have adopted "globalisation" to approach "pedagogical and social means" through the cultivation of "creativity, flexibility, independent thinking and innovation" (Ross and Lou 2005, p. 227). This view is reflected by the implementation of official music documents (MoE 2011, 2017), as well as the phenomenon that creativity is a social construct and interaction in which a product must be made. This is also what Staats (2011) viewed as the cultivation of creativity in Chinese culture that is closely related to "the cultural climate and controlling power" in Chinese society (p. 45). In addition to Chinese nationalism and Communism, Confucian ideology is seen as a challenge to creativity in school music education in China. The official approved songs and song lyrics are regarded as an attempt to explore the connections between creativity and Confucian values in both the family system and hierarchical social relationships (including students' obedience to teachers) in the curriculum (Ho 2019). According to a survey conducted by an international progress evaluation group in 2008, the findings showed that Chinese students' calculation ability was ranked first in the world; nonetheless, their creativity ranked fifth from the bottom and their 
imagination ranked last (People's Daily News 4 August 2010). Issues concerning the historical development of the Confucian education tradition are seen as challenges to the implementation of school education reforms. Questions have also been raised about the extent to which the Confucian education tradition will accept and favour the implementation of creativity in the school curriculum.

Many Beijing teachers in the study, however, reflected that their perceptions of the aims of school music education mainly stressed delivering music instruction to cultivate students to appreciate different music cultures and to expand the development of aesthetic education (see MoE 2011). With regard to the aims of music education, the role of creativity in music education and the importance of creative self-expression in school music education was not mentioned or discussed (though self-expression was mentioned by one teacher in the study). Even though creativity is mentioned in the official curriculum, it may be the case that the Chinese authorities' highly top-down reforms of teacher education and the school curriculum may have hindered teachers' creativity teaching in school (see MoE 2011; Staats 2011; Woronov 2008). Only one teacher pointed out that she advocated creativity in school education, as many of her students would further their studies in the USA and the UK, and schools were being pushed to integrate creativity as a competitive advantage. The other teachers in this study might have been influenced by the traditional Chinese teaching that individuality should not be encouraged in classroom teaching. As found by Campbell and $\mathrm{Hu}$ (2010), not much time is spent on creativity and innovation during teacher preparation, as well as on the introduction of new education reforms in China. The teachers described the practicum system as the continuation of traditional practices rather than an emphasis on innovative teaching strategies. There should be a more conscious role for teachers in response to their support of official teaching materials, one that includes a suitable point of equilibrium between political and social expectations and their professional image and identity. Guiding teachers in the school context creatively, musically, and ideologically is a critical problem in China's school music education. An innovative model for training teachers in both pre-service and in-service programmes could encourage creativity education to cultivate students' musical imagination as proposed in the official music curriculum guidelines (MoE 2011).

Second, there is a need to make school music education a vital means for the cultivation of creativity and culture for both teachers and students in educational practice. Though the teachers in the study did not express political concerns about the development of creativity in school music education and did not view the extent of the aims and values of school music education as being framed by political considerations, they maintained that their teaching materials were highly related to the official approved music textbooks. The teachers' use of textbooks was clear in the study, but it was not necessarily clear whether these textbooks had materials for teaching creativity in their music teaching (see Ho 2019). Given this circumstance, some teachers in the study related that whether they taught or did not teach creativity was highly in response to the approved textbook materials for teaching creativity. As noted in the MoE report (2017), the design of the textbooks "follows the correct political direction and insists on the correct political standpoint", and the contents of 
the textbook aim to strengthen "students" moral education" and to "pass on the core value of socialism" (p. 1).

The results of the study indicated that in addition to relevant teaching materials, the professional development of teachers and instructional reforms are necessary to remain compatible with teaching creativity. Though creative music-making is encouraged in the approved music textbooks and official documents, most teachers reflected that creative music-making was limited in their classroom teaching. One teacher even stressed that she had no means to teach creativity in her music classroom and she only adopted her students' popular idols' songs. Many teachers also admitted that they lacked confidence in leading creativity lessons and some of them were heavily reliant on music textbooks. The teachers' recommendations included research on teacher preparation programmes' inclusion of creativity and professional development opportunities.

Challenges and limitations remain in introducing creative pedagogies to support a pedagogical shift from traditional pedagogic practices to creativity-fostering pedagogic practices in school music education. Schools and teachers continue to face an ongoing "political correctness campaign" to maintain "correct political direction" and to uphold "correct political direction" as the basic principle of school education, as well as the criteria for selecting appropriate curriculum materials in China. On the one hand, China's modern economy is driven by creativity and innovation in society and in education. On the other hand, school education continues to face the challenge of nurturing students' creativity in the music curriculum within the context of the Chinese political culture. For more impacts and more specific directions for teachers regarding how to teach creativity across music genres and through music activities, teachers should be encouraged to develop their own practices together with the official curriculum and students' experiences in their creative learning.

\section{Conclusion}

This chapter has demonstrated the extent to which the politics of diversity in China has influenced creativity by requiring teachers to navigate between Confucianist educational policies that value obedience and order and the aims and values of creativity in school music education. This was clearly seen by the teachers' dilemmas in implementing creativity education via official music textbooks (or interpreted as official curricular policies). Despite the call to promote creativity in music education at the government policy level, the complex policy context has major implications for the implementation process in the interplay of Chinese policies, teachers' education, and the extent of the teachers' translation of the policies in practice in the music classroom. The challenge to music teachers and to teacher education is, respectively, to practise the diversity of Chinese politics in promoting both creativity and Confucianism in school music instruction and to support music teachers in introducing creativity through curriculum implementation. The integration of Chinese national identity and Confucian education into creativity 
education has been described as transformative and situational, but it is also subject to the continual negotiation of identity and tradition within the political fabric and ideology of the Chinese Government. Building on and extending the growing body of research on creativity and music education in China therefore provides a locus for the (re-)enactment of official institutional arrangements for creativity and school education, as well as negotiating and affirming the values that underpin them, in today's rapidly changing political and cultural landscape.

Acknowledgements The study presented in this chapter was a pilot study prepared for and generated from the project HKBU 12608618, generously supported by the Research Grants Council of Hong Kong, without which the production of this chapter would not have been feasible. The author expresses her heartfelt thanks to Beijing's music teachers who participated in the study.

\section{References}

Ambrogio, S. (2017). Moral education and ideology: The revival of Confucian values and the harmonious shaping the new Chinese man. Asian Studies, 5(2), 113-135. https://doi.org/10. 4312/as.2017.5.2.113-135.

Billioud, S., \& Thoraval, J. (2009). Lijiao: The return of ceremonies honouring confucius in Mainland China. China Perspectives, 4, 82-100. https://doi.org/10.4000/chinaperspectives. 4927.

Braun, V., \& Clarke, V. (2006). Using thematic analysis in psychology. Qualitative Research in Psychology, 3, 77-101. https://doi.org/10.1191/1478088706qp063oa.

Campbell, A., \& Hu, X. (2010). Professional experience reform in China: Key issues and challenges. Asia-Pacific Journal of Teacher Education, 38(3), 235-248. https://doi.org/10.1080/ 1359866X.2010.494004.

Cui, J. (2017, September 12). Traditional culture training set for Beijing teachers. China Daily. http://www.chinadaily.com.cn/china/2017-09/12/content_31888767.htm. Accessed 3 June 2020.

Gao, C. (2017, September 5). New Chinese textbooks: Now with more 'socialist core values'. The Diplomat. https://thediplomat.com/2017/09/new-chinese-textbooks-now-with-more-socialistcore-values/. Accessed 3 June 2020.

Guo, S. J. (2013). National acts for transmission of Chinese culture and heritage in arts education. In S. Leong \& B. W. Leung (Eds.), Creative arts in education and culture perspectives from greater China (pp. 15-26). Dordrecht: Springer. https://doi.org/10.1007/978-94-007-7729-3.

Ho, W. C. (2010). Moral education in China's music education: Development and challenges. International Journal of Music Education, 28(1), 71-87. https://doi.org/10.1177/ 0255761409351351.

Ho, W. C. (2017). China: Socio-political perspective on the introduction and development of school music. In G. Cox \& R. Stevens (Eds.), The origins and foundations of music education: International perspectives (pp. 240-255). London: Bloomsbury.

Ho, W. C. (2019). The challenge of teaching creativity in school music education in Mainland China. In Y. Tsubonou, A. G. Tan, \& M. Oie (Eds.), Creativity in music education (pp. 167-185). Singapore: Springer.

Lau, M. (2016, December 6). Class ideology: China's education chiefs order schools to roll out patriotic campaign on new media. South China Morning Post. https://www.scmp.com/news/ china/policies-politics/article/1911336/class-ideology-chinas-education-chiefs-order-schools. Accessed 3 June 2020.

Liu, S. X. (2016). Innovation design: Made in China 2025. Designed Management Review, 27(1), $52-58$. 
Liu, S. N., \& Feng, D. M. (2015). How culture matters in educational borrowing? Chinese teachers' dilemmas in a global era. Cogent Education, 2(1). https://www.cogentoa.com/article/10.1080/ 2331186X.2015.1046410.pdf.

Ministry of Education. (2001). Yinyue kecheung biaozhun: shiyan gao [Standard of music curriculum: Experimental version]. Beijing: Beijing Normal University Press.

Ministry of Education. (2011). Yiwu jiaoyu yinyue kecheng biaozhun [Compulsory educationnational music curriculum standardization]. Beijing: Beijing Normal University.

Ministry of Education. (2017). Putong gaozhong yinyue kecheng biaozhun [Curriculum standards for senior secondary education: Music]. Beijing: People's Education Press.

People's Daily News. (2010, August 4). Chinese students lack imagination, creativity. http://en. people.cn/90001/90776/90882/7093100.html. Accessed 3 June 2020.

Ross, H., \& Lou, J. J. (2005). "Glocalizing" Chinese higher education: Groping for stones to cross the river. Indiana Journal of Global Legal Studies, 12(1), 227-250.

Staats, L. K. (2011). The cultivation of creativity in the Chinese culture - Past, present, and future. Journal of Strategic Leadership, 3(1), 45-53.

Watkins, D. A., \& Biggs, J. B. (2001). Teaching the Chinese learner: Psychological and pedagogical perspectives. Hong Kong: Comparative Education Research Centre, the University of Hong Kong.

Woronov, T. E. (2008). Raising quality, fostering "creativity": Ideologies and practices of education reform in Beijing. Anthropology \& Education Quality, 39(4), 401-422.

Xinhua Net. (2018, September 10). Chinese focus: Xi stresses following path of socialist education with Chinese characteristics. http://www.xinhuanet.com/english/2018-09/10/c_137459026. htm. Accessed 3 June 2020.

Xiong, X. H., \& Zheng, Y. H. (2012). Yiwu yinyue kecheung biaozhun - 2011 nianpan [Compulsory education music curriculum standardisation - 2011 version]. Journal of Beijing Institute of Education, 26(6), 71-76.

Xu, M. (2016). Zhongguo yishi jiaoyu de daode jiaoyu gongneng [Function of moral education in Chinese arts education]. Ability and Wisdom (Caizhi), 23, 56.

Yau, E. (2018, October 25). How China is leveraging Confucianism to boost cultural tourism. South China Morning Post. https://www.scmp.com/lifestyle/travel-leisure/article/2169824/howchina-leveraging-confucianism-boost-cultural-tourism. Accessed 3 June 2020.

Yin, R. K. (2014). Case study research: Design and methods. Thousand Oaks: Sage. https://doi.org/ 10.3138/cjpe.30.1.108.

Zhang, W. Z. (2017). Multicultural ethnic music education in Communist China. International Journal of Multicultural Education, 19(3), 65-84. https://doi.org/10.18251/ijme.v19i3.1359.

Zhao, L. (2009). Shilun yinyue jiaoyu zai sixiang jiaoyu zhong de zuoyong [critics on the function of moral education in music education]. Journal of Liaoning Educational Administration Institute, 26(2), 122.

Zhao, Y. (2012). Flunking innovation and creativity. The Phi Delta Kappan, 49(1), 56-61.

Zhou, J., Shen, J. L., Wang, X. H., Neber, H., \& Johji, I. (2013). A cross-cultural comparison: Teachers' conceptualizations of creativity. Creativity Research Journal, 25(3), 239-247. https:// doi.org/10.1080/10400419.2012.730006.

Wai-Chung Ho is a professor in the Department of Music at Hong Kong Baptist University. Her substantive research interests include the sociology of music, China's music education, and the comparative study of East Asian music education. Her research has focused on interlinked areas of social and political development, education policy, and reform in school education, as well as on values in education across school curricula in Chinese contexts, including Mainland China, Hong Kong, and Taiwan. 
Open Access This chapter is licensed under the terms of the Creative Commons Attribution 4.0 International License (http://creativecommons.org/licenses/by/4.0/), which permits use, sharing, adaptation, distribution and reproduction in any medium or format, as long as you give appropriate credit to the original author(s) and the source, provide a link to the Creative Commons license and indicate if changes were made.

The images or other third party material in this chapter are included in the chapter's Creative Commons license, unless indicated otherwise in a credit line to the material. If material is not included in the chapter's Creative Commons license and your intended use is not permitted by statutory regulation or exceeds the permitted use, you will need to obtain permission directly from the copyright holder. 